This article is licensed under the Creative Commons Attribution-NonCommercial 4.0 International License (CC BY-NC) (http://www.karger.com/Services/OpenAccessLicense). Usage and distribution for commercial purposes requires written permission.

\title{
Periorbital Ecchymosis (Raccoon Eye) and Orbital Hematoma following Endoscopic Retrograde Cholangiopancreatography
}

\author{
Jafar Nasiri ${ }^{\mathrm{a}} \quad$ Farhad Zamani $^{\mathrm{b}}$ \\ a Department of Internal Medicine, Shaharekord University of Medical Sciences, \\ Shahrekord, Iran; ${ }^{b}$ Gasterointestinal and Liver Disease Research Center (GILDRC), Iran \\ University of Medical Sciences, Tehran, Iran
}

\section{Keywords}

Eye $\cdot$ Ecchymosis · Cholangiopancreatography $\cdot$ Endoscopic retrograde cholangiopancreatography

\begin{abstract}
Endoscopic retrograde cholangiopancreatography (ERCP) is a conventional technique for diagnosis and treatment of pancratobiliary diseases, which is associated with various complications, including pancreatitis, hemorrhage, cholangitis, perforation, and mortality. In our case, a 69-year-old woman with positive hepatobiliary symptoms underwent ERCP, at the end of which a rare complication (raccoon eye) occurred, which was hypothesized to be due to amyloidosis, but the patient refused to complete the diagnostic procedure and became symptom free after 3 weeks. Racoon eye or periorbital ecchymosis is caused by blood tracking into periorbital tissues, which is frequently observed after head trauma but is also observed in systemic diseases, such as amyloidosis, neuroblastoma, and surgical interventions. To the best of our knowledge, this is the first report of raccoon eye after ERCP; further re-
\end{abstract}




\section{Case Reports in Gastroenterology}

Case Rep Gastroenterol 2017;11:134-141

(c) 2017 The Author(s). Published by S. Karger AG, Basel www.karger.com/crg

Nasiri and Zamani: Periorbital Ecchymosis (Raccoon Eye) and Orbital Hematoma following Endoscopic Retrograde Cholangiopancreatography

ports will help to confirm that this complication should also be considered before performing ERCP and that complete diagnostic tests for the predisposing diseases prior to ERCP are necessary.

(C) 2017 The Author(s)

Published by S. Karger AG, Basel

\section{Introduction}

Endoscopic retrograde cholangiopancreatography (ERCP) is the fiberoptic endoscopy designed to visualize the pancreatic and biliary duct system by retrograde injection of contrast media, which is an appropriate tool for the diagnosis and management of hepatobiliary diseases. However, as an invasive method, it can be associated with severe complications, including pancreatitis, hemorrhage, cholangitis, perforation, and mortality [1, 2], while several methods have been suggested to reduce such complications [3]. Nevertheless, the documented complications are mainly limited to the hepatobiliary tract [2].

Periorbital ecchymosis or raccoon eye is produced by blood tracking into periorbital tissues, causing blue or purple discoloration of the upper and lower eyelids, which is a frequent symptom after traumatic injuries to the head and neck, including basal skull fractures, soft tissue injuries, convexity fractures, and facial fractures, which occurs due to the contusion and stretching of capillaries [4]. Also, some studies have reported bilateral periorbital ecchymosis as a rare symptom in a number of systematic diseases, such as primary amyloidosis [5] and migraine [6]. The coagulopathy and vascular infiltration of amyloid fibrils in periorbital blood vessels in patients with amyloidosis can cause bilateral periorbital ecchymosis by minimal trauma, such as sneezing, coughing, or rubbing [7]. In general, the conditions suggested to cause periorbital ecchymosis include disorders increasing venous pressure, causing fragile capillaries, or impairing the coagulation state [8]. Ecchymosis is also observed in several malignancies, including neuroblastoma [9] and multiple myeloma [10]. Some cases of periorbital ecchymosis have been reported to occur after procedures and interventions such as ear surgery [11], globe injury [12], rhinoplasty [13], sinus surgery [14], and continuous positive airway pressures [8].

Yet, there are very few case reports of the occurrence of this symptom after endoscopic procedures. Tas [15] reported a case of unilateral periorbital ecchymosis in a 70-year-old man undergoing upper gastrointestinal endoscopy, which resolved after 15 days. Some researchers have also reported postproctoscopic purpura $[16,17]$. However, to the best of our knowledge, no cases of periorbital ecchymosis has been reported after ERCP in the literature. We report a patient with periorbital ecchymosis (raccoon eye) following ERCP and sphincterotomy.

\section{Case Presentation}

A 69-year-old woman was referred to our clinic with the chief complaint of chronic abdominal pain in the right upper quadrant and epigastric area that began 5 months ago and had a frequency of once to twice per weak, each episode lasting 2-3 h. In her medical history, she had a positive history of chronic rheumatoid arthritis starting 8 years ago, for which she 


\section{Case Reports in Gastroenterology}

Case Rep Gastroenterol 2017:11:134-141

(c) 2017 The Author(s). Published by S. Karger AG, Basel www.karger.com/crg

Nasiri and Zamani: Periorbital Ecchymosis (Raccoon Eye) and Orbital Hematoma following Endoscopic Retrograde Cholangiopancreatography

received $400 \mathrm{mg}$ ibuprofen (p.r.n.), $250 \mathrm{mg}$ chloroquine, and $5 \mathrm{mg}$ prednisolone every day. But the patient had no history of aspirin, warfarin, or heparin.

Physical examination revealed only mild tenderness in the metacarpophalangeal joints and mild tenderness in the right upper quadrant and epigastric area and no palpable splenomegaly or hepatomegaly. Alkaline phosphatase was $475 \mathrm{IU} / \mathrm{L}$ (normal range: 50-250 IU/L). Aminotransferases, total serum bilirubin, and complete blood cell count were within normal ranges (Table 1). Hepatobiliary ultrasonography was unremarkable.

She was subjected to a magnetic resonance cholangiopancreatography, which revealed common bile duct dilatation and papillary stenosis (Fig. 1). For better evaluation, she underwent ERCP that demonstrated common bile duct dilatation and papillary stenosis (Fig. 2). She developed bilateral orbital and periorbital ecchymosis just before termination of ERCP and sphincterotomy, within a few minutes (Fig. 3).

According to her history of chronic rheumatoid arthritis, normal coagulation profile (prothrombin time, partial thromboplastin time, and platelet count), and negative history of recent nonsteroidal anti-inflammatory drugs, the possibility of amyloidosis was considered. But the patient refused any endoscopic or other invasive procedures (biopsy from the second portion of the duodenum or abdominal fat pad aspiration) for documentation of amyloidosis.

After 3 weeks, the patient had completely recovered.

\section{Discussion}

Raccoon eye is the hallmark sign of skull fracture following trauma, but it may also rarely occur in a number of nontraumatic diseases, such as migraine [6], neuroblastoma [9], and amyloidosis [5], associated with multiple myeloma [10].

In our case, the patient refused to undergo further investigation for documentation of amyloidosis, which could have been the underlying disease of raccoon eye; yet, the occurrence of this symptom at the end of the ERCP procedure suggests that it may be a complication of ERCP. In addition, amyloidosis is a systemic disease that affects multiple organs (including the kidney, heart, nervous system, soft tissues, lungs, and liver) and has several signs and symptoms [18], while the patient in our case report did not have the common symptoms of amyloidosis; even the gastrointestinal symptoms of our patient did not match the gastrointestinal symptoms of amyloidosis [19].

Very few studies have reported periorbital ecchymosis following endoscopic procedures. Tas [15] reported a case of unilateral periorbital ecchymosis in a 70-year-old man undergoing upper gastrointestinal endoscopy, which resolved after 15 days. Similar to that case, our patient's raccoon eye also resolved after 2 weeks. Also, in the studies reporting postproctoscopic purpura, it was a temporary sign $[16,17]$. Thus, it can be concluded that the occurrence of raccoon eye after endoscopic interventions is transient, but conditions that predispose the patients to this complication have to be determined prior to such interventions.

As suggested, conditions suggested to cause bilateral periorbital ecchymosis include disorders increasing the arterial pressure, causing fragile capillaries, or impairing the coagulation state $[7,8]$. Therefore, it is essential to evaluate the above-mentioned conditions in 
patients who are candidates for endoscopic examinations. In our case, several serum parameters were checked before magnetic resonance cholangiopancreatography/ERCP, which revealed a normal coagulation profile (prothrombin time, partial thromboplastin time, and platelet count). For that reason, there were no possible reasons for the above-mentioned disorders to cause bilateral periorbital ecchymosis. Thus, we hypothesized that the consumption of ibuprofen and prednisolone in addition to the prone positioning in ERCP and possible Valsalva maneuver during the procedure might have caused raccoon eye in the patient, as she might have had fragile vessels due to her age and increased venous pressure that led to this complication. Nevertheless, we should not omit the possibility of amyloidosis, which could not be confirmed or ruled out because of the lack of the patient's consent to further investigations.

Alternatively, some studies have reported raccoon eye following vigorous sneezing [20], and there was a recurrent case due to vomiting [21], which suggests that this condition may also occur after benign conditions that increase venous pressure and does not necessarily point to a severe disease.

But the scarcity of data on this issue limits a profound discussion and judgement; thus, it is suggested that future studies further investigate the predisposing factors for bilateral periorbital ecchymosis. To the best of our knowledge, the present report is the first report of raccoon eye after ERCP; further reports will help to confirm that this complication should also be considered before performing ERCP and that complete diagnostic tests for the predisposing diseases prior to ERCP are necessary.

\section{Statement of Ethics}

This article has been performed according to the World Medical Association Declaration of Helsinki Ethical Principles for Medical Research Involving Human Subjects.

\section{Disclosure Statement}

The authors declare that they have no conflicts of interest regarding the publication of this paper.

\section{References}

1 Masci E, Toti G, Mariani A, et al: Complications of diagnostic and therapeutic ERCP: a prospective multicenter study. Am J Gastroenterol 2001;96:417-423.

2 Christensen M, Matzen P, Schulze S, Rosenberg J: Complications of ERCP: a prospective study. Gastrointest Endosc 2004;60:721-731.

-3 Hauser G, Milosevic M, Stimac D, et al: Preventing post-endoscopic retrograde cholangiopancreatography pancreatitis: what can be done. World J Gastroenterol 2015;21:1069-1080. Somasundaram A, Laxton AW, Perrin RG: The clinical features of periorbital ecchymosis in a series of trauma patients. Injury 2014;45:203-205. 


\section{Case Reports in \\ Gastroenterology} \begin{tabular}{l|l}
\hline Case Rep Gastroenterol 2017;11:134-141 \\
\hline DOI: 10.1159/000456657 & $\begin{array}{l}\text { C } 2017 \text { The Author(s). Published by S. Karger AG, Basel } \\
\text { www.karger.com/crg }\end{array}$ \\
\hline
\end{tabular}

Nasiri and Zamani: Periorbital Ecchymosis (Raccoon Eye) and Orbital Hematoma following Endoscopic Retrograde Cholangiopancreatography

5 Weingarten TN, Hall BA, Richardson BF, Hofer RE, Sprung J: Periorbital ecchymoses during general anesthesia in a patient with primary amyloidosis: a harbinger for bleeding? Anesth Analg 2007;105:1561-1563. DeBroff BM, Spierings EL: Migraine associated with periorbital ecchymosis. Headache 1990;30:260263.

7 Colucci G, Alberio L, Biasiutti FD, Lämmle B: Bilateral periorbital ecchymoses. Hämostaseologie 2014;34:249-252.

DelRosso L, McCarty DE, Hoque R: "Why did my CPAP beat me up?" Bilateral periorbital ecchymosis associated with continuous positive airway pressure therapy. J Clin Sleep Med 2012;8:730. Moran DE, Donoghue V: Periorbital ecchymosis ("raccoon eyes") as the presenting feature of neuroblastoma. Pediatr Radiol 2010;40:1710-1710. Varım C, Ergenc H, Uyanık MS, et al: A very rare presentation of multiple myeloma: unilateral raccoon eye. Open Access Maced J Med Sci 2015;3:436-438.

11 Rajati M, Bakhshaee M, Khazaeni K: Periorbital ecchymosis and subconjunctival hemorrhage following ear surgery. ISRN Otolaryngol 2013;2013:791068.

12 Ghazi-Nouri SM, Vote BJ, Sullivan PM: Periorbital ecchymosis as a sign of perforating injury of the globe. Clin Exp Ophthalmol 2005;33:194-196.

13 Al Arfaj AM: The use of nasal packing post rhinoplasty: does it increase periorbital ecchymosis? A prospective study. J Otolaryngol Head Neck Surg 2015;44:1.

14 Seredyka-Burduk M, Burduk PK, Wierzchowska M, Kaluzny B, Malukiewicz G: Ophthalmic complications of endoscopic sinus surgery. Braz J Otorhinolaryngol 2016, Epub ahead of print.

-15 Tas A: Periorbital ecchymosis following an upper gastrointestinal endoscopy. Gastroenterol Nurs 2013;36:72.

$>16$ Slagel GA, Lupton GP: Postproctoscopic periorbital purpura. Arch Dermatol 1986;122:465-466. Truniger B, Gebbers J: PPPP (post-proctoscopy periorbital purpura) (in German). Schweiz Med Wochenschr 1998;128:311.

18 de Asúa DR, Costa R, Galván JM, et al: Systemic AA amyloidosis: epidemiology, diagnosis, and management. Clin Epidemiol 2014;6:369.

19 Lim AY, Lee JH, Jung KS, et al: Clinical features and outcomes of systemic amyloidosis with gastrointestinal involvement: a single-center experience. Korean J Intern Med 2015;30:496-505. Maramattom BV: Raccoon eyes following vigorous sneezing. Neurocrit Care 2006;4:151-152. Hussain A-S: Recurrent bilateral periorbital and circumoral bruising due to vomiting. BMJ Case Rep 2014;2014:bcr2013202495. 


\section{Case Reports in Gastroenterology} www.karger.com/crg

Nasiri and Zamani: Periorbital Ecchymosis (Raccoon Eye) and Orbital Hematoma following Endoscopic Retrograde Cholangiopancreatography

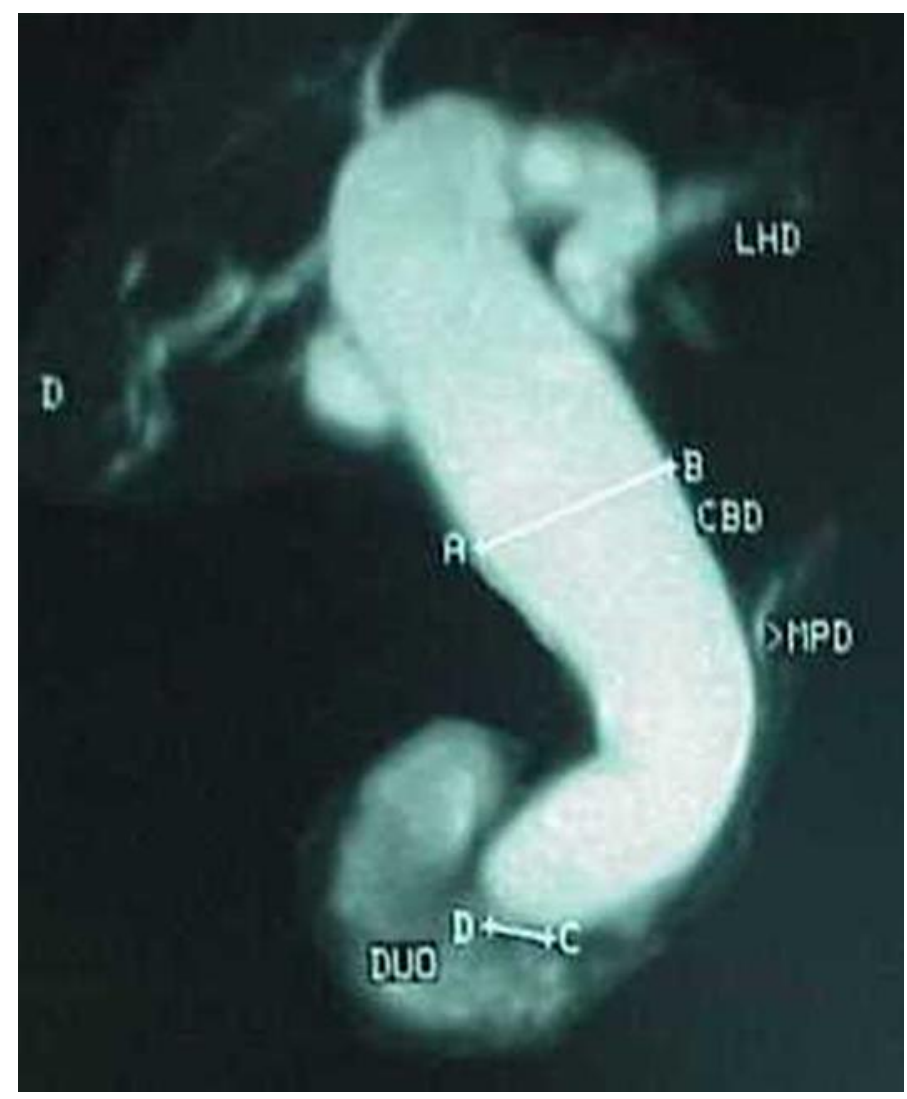

Fig. 1. Magnetic resonance cholangiopancreatography evaluation of the patient which revealed common bile duct dilatation and papillary stenosis. 


\section{Case Reports in Gastroenterology}

Case Rep Gastroenterol 2017:11:134-141

DOI: $10.1159 / 000456657$

(C) 2017 The Author(s). Published by S. Karger AG, Basel www.karger.com/crg

Nasiri and Zamani: Periorbital Ecchymosis (Raccoon Eye) and Orbital Hematoma following Endoscopic Retrograde Cholangiopancreatography

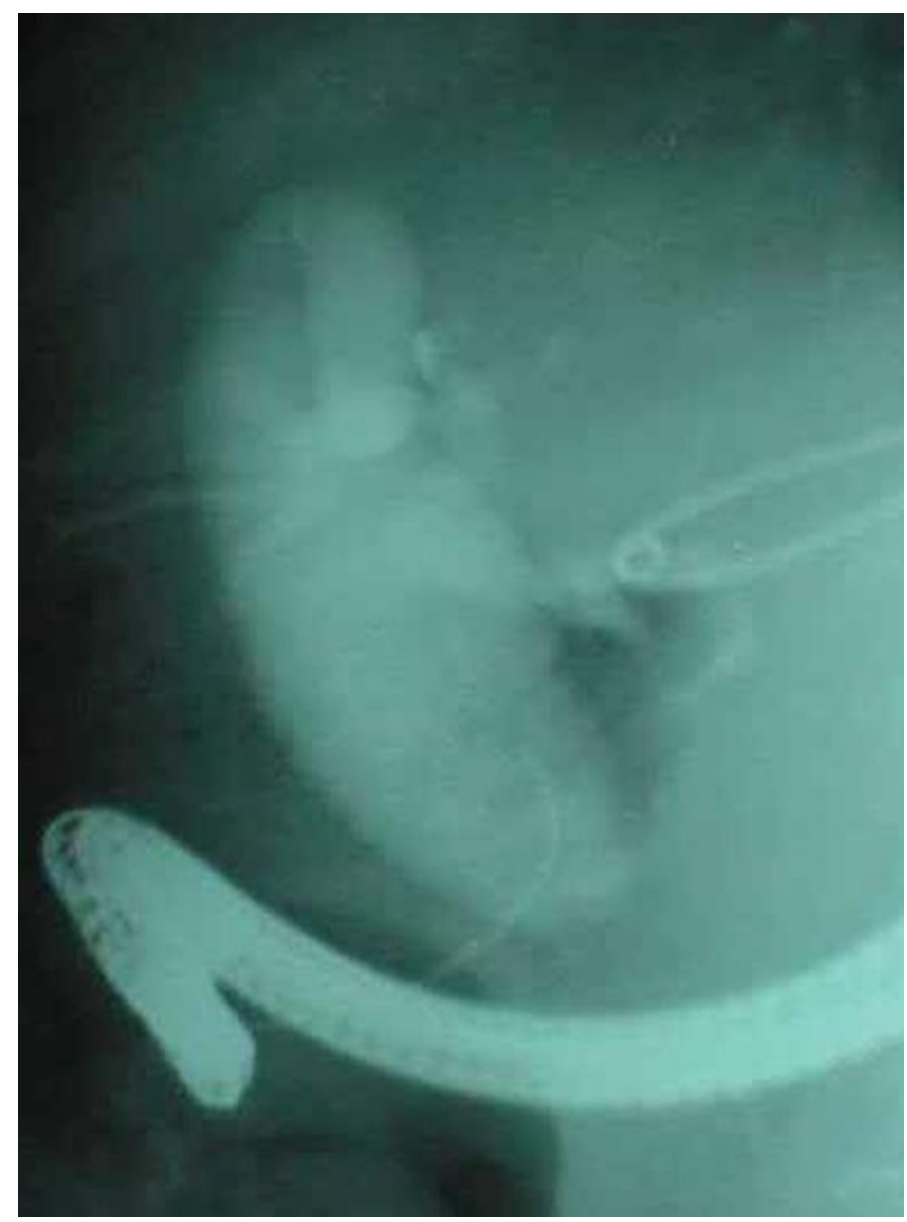

Fig. 2. Endoscopic retrograde cholangiopancreatography evaluation of the patient demonstrating common bile duct dilatation and papillary stenosis without obvious stone or mass lesion.

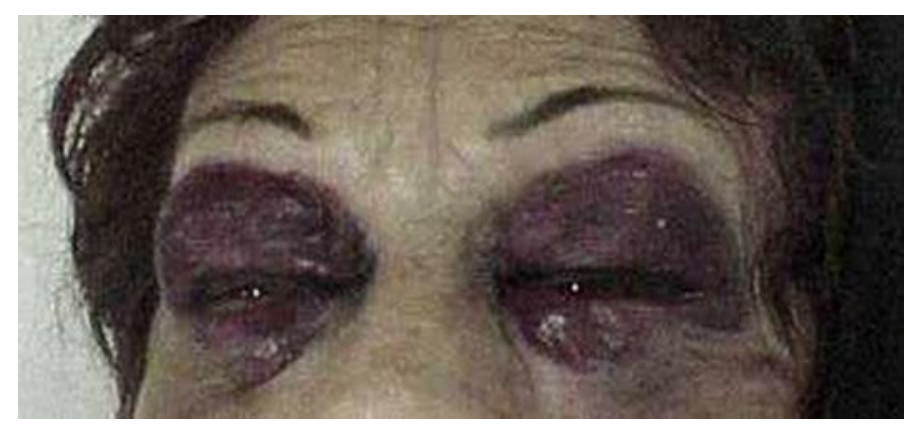

Fig. 3. Typical raccoon sign following endoscopic retrograde cholangiopancreatography. 


\section{Case Reports in Gastroenterology}

Case Rep Gastroenterol 2017;11:134-141

C 2017 The Author(s). Published by S. Karger AG, Basel www.karger.com/crg

Nasiri and Zamani: Periorbital Ecchymosis (Raccoon Eye) and Orbital Hematoma

following Endoscopic Retrograde Cholangiopancreatography

Table 1. Results of serum examinations of the patient

\begin{tabular}{lcc}
\hline & Patient's value & Normal range \\
\hline Alkaline phosphatase, IU/L & 475 & $50-250$ \\
Alanine aminotransferase, IU/L & 31 & $5-35$ \\
Aspartate aminotransferase, IU/L & 27 & $5-35$ \\
Total bilirubin, mg/dL & 0.9 & $0.2-1$ \\
Prothrombin time, s & 13 & $11-14$ \\
Partial thromboplastin time, s & 32 & $25-42$ \\
Hemoglobin, g/dL & 12.8 & $12-16$ \\
White blood cells, count/mm 35 & 7,315 & $3,800-10,000$ \\
Platelet, count/mm & & $140,000-350,000$ \\
Blood urea nitrogen, mg/dL & 164,200 & $8-20$ \\
Creatinine, mg/dL & 23 & $0.8-1.2$ \\
Estimated sedimentation rate, mm & 1.1 &
\end{tabular}

